Research Paper

\title{
NOX2 Antisense Attenuates Hypoxia-Induced Oxidative Stress and Apoptosis in Cardiomyocyte
}

\author{
Bo Yu, Fanbo Meng, Yushuang Yang, Dongna Liu, Kaiyao Shi ${ }^{凶}$ \\ Department of cardiology, China-Japan union hospital of Jilin University, Changchun, Jilin, 130033, P.R. China \\ $\triangle$ Corresponding author: Dr. Kaiyao Shi, Department of cardiology, China-Japan union hospital of Jilin University, Changchun, Jilin,130033, P.R. China. 126 \\ Xiantai Street, Changchun, Jilin, P.R. China. Tel.: 0431-84995308, Fax: 0431-84641026, E-Mail: shiky@jlu.edu.cn \\ (C) Ivyspring International Publisher. Reproduction is permitted for personal, noncommercial use, provided that the article is in whole, unmodified, and properly cited. See \\ http://ivyspring.com/terms for terms and conditions.
}

Received: 2016.02.02; Accepted: 2016.06.25; Published: 2016.07.27

\begin{abstract}
Heart ischemia is a hypoxia related disease. NOX2 and HIF-1a proteins were increased in cardiomyocytes after acute myocardial infarction. However, the relationship of the hypoxia-induced HIF-1 $\alpha$. NOX2-derived oxidative stress and apoptosis in cardiomyocyte remains unclear. In the current study, we use NOX2 antisense strategy to investigate the role of NOX2 in hypoxia-induced oxidative stress and apoptosis in rat cardiomyocytes. Here, we show that transduction of ADV-NOX2-AS induces potent silencing of NOX2 in cardiomyocytes, and resulting in attenuation of hypoxia-induced oxidative stress and apoptosis. This study indicates the potential of antisense-based therapies and validates NOX2 as a potent therapeutic candidate for heart ischemia.
\end{abstract}

Key words: Heart ischemia, Heart infarction, NOX2, Oxidative stress, and apoptosis

\section{Introduction}

The antisense strategy is an established approach to specifically inhibit target gene expression and has been tested in vitro and in vivo $[1,2]$.

NOX2, known as gp91phox, was first discovered in neutrophils and macrophages [3] and was described later in nonphagocytic cells, including neurons [4], skeletal muscle myocytes [5], hepatocytes [6], endothelial cells [7-9], hematopoietic stem cells [10], and cardiomyocytes [11]. It has been confirmed that NOX2 was expressed in the cardiomyocytes in human heart and increased in the acute myocardial infarction in cardiomyocytes in patients [11-12].

The function of NOX2 is to produce superoxide, which is the major source of reactive oxygen species (ROS) [13]. ROS is a physiological byproduct in normal cellular aerobic metabolism. However, it acts as an oxidative stress marker that is increased under pathologic condition [14-16]. It has been demonstrated that hypoxia also induces ROS generation in myocardium. ROS stabilizes HIF-1 a in ischemic heart disease. The phenomenon was seen in patients with elevated HIF-1 a expression and ROS production $[17,18]$.

Here we focused on the hypothesis that NOX2 antisense can specifically attenuate cardiomyocyte apoptosis through the inhibition of hypoxia-induced increase in ROS production. To date, there is no NOX specific inhibitor existing although some inhibitors, such as Diphenylene iodonium [19], Apocynin [20], 4-(2-Aminoethyl)benzenesulfonylfluoride (AEBSF) [21], and Neopterin [22] were used to inhibit NOX enzymes.

We hypothesized that NOX2 antisense could specifically inhibit NOX2 expression and thus attenuate hypoxia-induced oxidative stress and cardiomyocyte apoptosis. The previous report demonstrated that cardiomyocyte apoptosis was involved in acute and chronic heart failure and ischemia-induced apoptosis through upregulation of NOX2 expression in cardiomyocytes [23, 24]. However, the relationship of hypoxia-induced HIF-1a, and NOX2-derived oxidative stress and apoptosis in cardiomyocyte remains unclear. In the current study, we used NOX2 antisense strategy to 
investigate the role of NOX2 in hypoxia-induced oxidative stress and apoptosis in rat cardiomyocytes.

\section{Materials and Methods}

\section{Construction of adenovirus with rat NOX2 anti-sense (ADV-NOX2 -AS)}

The NOX2 fragment (nt265-nt1312) was inserted into Adeno-X-viral DNA expression vector (BD Clontech) in reverse orientation. After digestion with I-CeuI and PI-SceI, ADV-NOX2 AS was packaged in HEK 293 cells (Fig. 1) and ADV-LacZ (BD Clontech) was used as the control vector.

\section{Cell culture}

Cardiomyocytes (H9C2, ATCC) were cultured at $37^{\circ} \mathrm{C}$ in complete medium (CM) containing $89 \%$ DMEM, $1 \%$ penicillin and streptomycin (life Tech) and 10\% FBS (Sigma) with 5\% CO2.

\section{Hypoxia induction}

The cells were cultured in CM with $100 \mu \mathrm{M}$ of Cobalt Chloride hexahydrate $(\mathrm{CoCl} 2$ - $6 \mathrm{H} 2 \mathrm{O}$, $\mathrm{MW}=237.9$ ) in a $5 \% \mathrm{CO} 2,37^{\circ} \mathrm{C}$ cell culture incubator for 24 hours. To induce hypoxia, the cells were cultured in $1 \% \mathrm{O} 2,5 \% \mathrm{CO} 2$ gas mixture for 24 hours $[25,26]$.

\section{Transduction of ADV-NOX2-AS}

The cells were grown in $\mathrm{CM}$ for 24 hours and then transduced with ADV-LacZ and ADV-NOX2-AS respectively at multiplicity of infection (MOI) 50, continuously cultured for 36 hours, and then induced hypoxia for 24 hours. These cells were used for all the experiments in this study.

\section{mRNA extraction}

The cells were harvested and washed twice with cold PBS. The cell pellet was homogenized in Trizol Reagent (Life Tech) for 30 seconds and centrifuged at $10,000 \mathrm{~g}$ for $15 \mathrm{~min}$ at $4^{\circ} \mathrm{C}$. The clear phase (top layer) was collected and 0.7 volume of isopropanol was added. The mix was centrifuged at $10,000 \mathrm{~g}$ for $15 \mathrm{~min}$ at $4^{\circ} \mathrm{C}$. The pellet was washed with $70 \%$ alcohol and dried out in the hood. The total RNA was dissolved in $30 \mu \mathrm{l}$ of water.

\section{RT-PCR}

A total of 10 ng of RNA was used to amplify NOX2 and HIF-1 a cDNAs with reverse transcriptase III. PCR was performed with PCR cycler (Bio Rad) using NOX2 primers: 5'-GGGCTGAATGTCTTC CTCTTT-3' (forward) and 5'-GGTACTGGGC ACTCCTTTATTT-3' (reverse) (IDTDNA); HIF-1 a primers: 5'-GGAAATGCTGGCTCCCTATATC-3' (forward) and 5'-GCTGTGGTAATCCACTCTCATC $-3^{\prime}$ (reverse) (IDTDNA); Rat $\beta$-actin as the control (Forward: 5'-CAACTGGGACGATATGGAGAAG-3', reverse: 5'-CTCGAAGTCTAGGGCAACATAG-3') (IDTDNA). PCR program was carried out for 30 cycles. Each cycle consisted of 30s of denaturation at $94^{\circ} \mathrm{C}, 40 \mathrm{~s}$ of annealing at $62^{\circ} \mathrm{C}$, and $60 \mathrm{~s}$ of extension at $72^{\circ} \mathrm{C}$, followed by a final 7 -min extension at $72^{\circ} \mathrm{C}$.

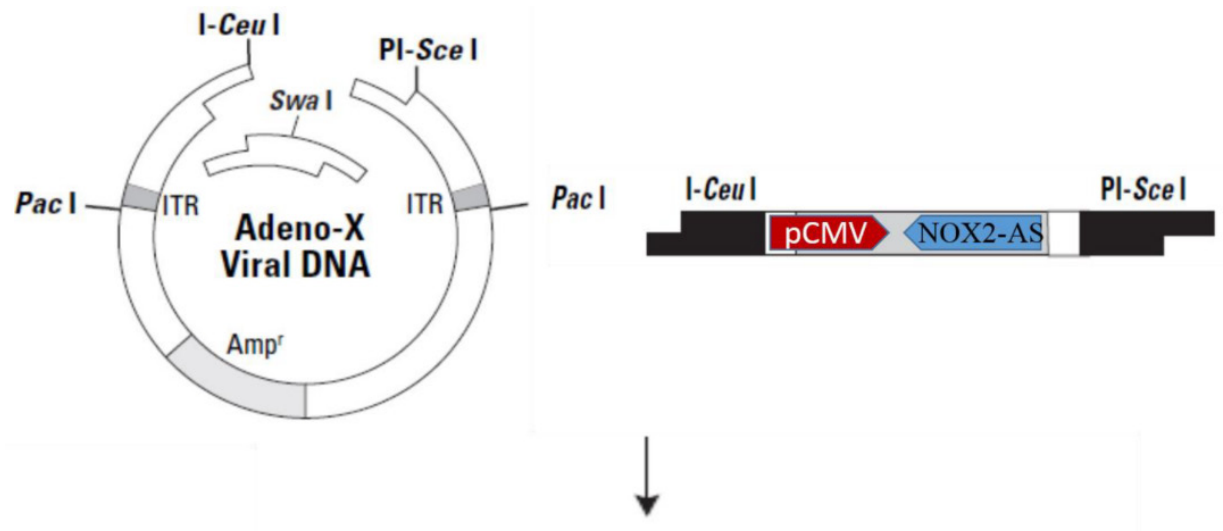

Transfect low-passage HEK 293 cells

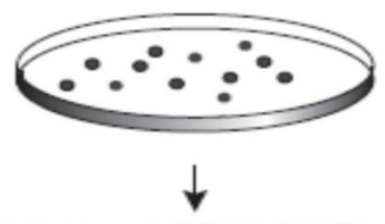

Collect recombinant adenovirus

Fig.1 Construction of recombinant ADV-NOX2-AS. Abbreviation: ADV, adenovirus; NOX2, NADPH oxidase family member 2, known as gP91phox; AS, anti-sense. 


\section{Western Blot}

The cells were harvested and lysed with RIPA buffer (cell signal) for $30 \mathrm{~min}$ on ice, then homogenized for 10s. The supernatant was obtained by centrifugation at speed $12,000 \mathrm{~g}$ for $15 \mathrm{~min}$ at $4^{\circ} \mathrm{C}$. A small volume of lysate was removed to perform a protein quantification assay. Determine the protein concentration for each cell lysate using $\mathrm{BCA} /$ microplate reader (Bio-Rad). The same amount of protein was loaded onto SDS-protein gel $(4-20 \%$, Genescript). The protein was transferred onto nitrocellulose. After blocking with 5\% BSA/TBS-T for one hour at room temperature, the membrane was then probed with mouse anti-NOX2 (BD Bioscience) or rabbit anti-HIF-1 a (abcam) primary antibody at $4^{\circ} \mathrm{C}$ overnight. After three washes with TBS-T, the secondary antibody, goat-anti mouse IgG-HRP (Santa Cruz) for mouse anti-NOX2 or goat-anti rabbit IgG-HRP (Santa Cruz) for rabbit anti-HIF-1 a was used respectively for developing in enhanced chemiluminescent (ECL) substrate (LifeTech).

\section{Immunocytochemistry}

The cells were grown in culture chamber. The treatment was the same as described above. The cells were washed twice with cold-PBS, air-dried for $5 \mathrm{~min}$ in culture hood, and fixed with 4\% PFA-PBS at room temperature for $10 \mathrm{~min}$. The fixed cells were then rinsed twice with PBS and blocked in 5\% BSA at $4^{\circ} \mathrm{C}$ overnight. The cells were probed (without rinsing) with the primary antibody, goat anti- NOX2 primary antibody (Santa Cruz) or rabbit anti-HIF-1 a (abcam) at $4^{\circ} \mathrm{C}$ overnight. After three washes with PBS, the cells were probed with donkey anti-goat-FITC for goat anti- NOX2 or goat anti-rabbit IgG-FITC for rabbit anti-HIF-1 a primary antibody. The fluorescent signal was viewed under the fluorescence microscope.

\section{Dihydroethidium (DHE) -flow cytometry}

DHE staining was performed according to Richard et al. [27]. Briefly, batch-cultured cells on chamber slides were rinsed with cold PBS, applied with DHE $(10 \mu \mathrm{g} / \mathrm{ml})$, and then incubated for $15 \mathrm{~min}$ at $30^{\circ} \mathrm{C}$ in dark. DHE was observed under fluorescence microscope. In DHE-flow cytometry assay, the cells were harvested by trypsin digestion, rinsed with cold-PBS, and then probed with DHE (10 $\mu \mathrm{g} / \mathrm{ml}$ ) for $15 \mathrm{~min}$ at $30^{\circ} \mathrm{C}$ in dark. The extra DHE was washed out by spinning down in cold-PBS, and the DHE-stained cells were re-suspended in cold-PBS for flow cytometry.

\section{Apoptotic assay-annexin V-FITC-flow cytometry}

Apoptosis was evaluated using Annexin V-FITC
Apoptosis Detection Kit (abcam). Immediately after initiating apoptosis, cells translocate the membrane phosphatidylserine (PS) from the inner face of the plasma membrane to the cell surface. Once on the cell surface, PS can be easily detected by staining with a fluorescent conjugate of Annexin V, a protein that has a high affinity for PS. The FITC-positive cells were counted by flow cytometer.

\section{Apoptotic assay}

ApoBrdU-IHC DNA Fragmentation AssayTUNEL: Apoptotic cells can be detected by terminal deoxynucleotidyl transferase (TdT)-mediated dUTP nick end labeling (TUNEL). The stain protocol was performed according to the manual of ApoBrdU-IHC DNA Fragmentation Assay Kit (Biovision).

\section{Lucigenin-enhanced NADPH oxidase activity}

The batch-treated cells were harvested and rinsed once with cold-PBS, and the cell pellet was re-suspended in $200 \mu \mathrm{l}$ of lucigenin $(10 \mu \mathrm{M}$,sigma) and incubated at room temperature for $20 \mathrm{~min}$ in dark. The basal level of NADPH oxidase activity was measured. A total of $5 \mu$ l of NADPH $(100 \mu \mathrm{M}$, sigma $)$ was added, and its oxidase activity was continuously measured every $2 \mathrm{~min}$ for 5 times. The unit was expressed in RUL/min cell.

\section{Statistical Analysis}

Data were analyzed by $t$ test. Significance level was set as $\alpha=0.05$ (95\% Confidence Level).

\section{Results}

\section{ADV-NOX2-AS attenuated NOX2 mRNA and protein expression in hypoxia-induced cardiomyocytes}

NOX2 is a transmembrane protein with molecular weight about 90kda. Western blot (Fig. 2 A) and In situ immunocytochemistry (Fig. 2 C) data showed that NOX2 protein and hypoxia-inducible factor (HIF-1a) were increased in hypoxia cells transfected with ADV-LacZ (Hypoxia-ADV-LacZ) compared with normoxia cells transfected with ADV-LacZ (normoxia-ADV-LacZ). Expectedly, both NOX2 and HIF-1 a proteins were reduced in ADV-NOX2-AS-treated hypoxia (hypoxia-ADVNOX2-AS) cells compared with hypoxia-ADV-LacZ. The mRNA levels of NOX2 (712bp) and HIF-1 a (698bp) were also increased in hypoxia-ADV-LAcZ treated cardiomyocytes compared with the normoxia-ADV-LacZ treated cells. However, ADV-NOX2-AS attenuated the hypoxia-induced increase in NOX2 and HIF-1 a mRNA (Fig. 2B). The $\beta$-actin (442bp) served as a control mRNA remained no change. 

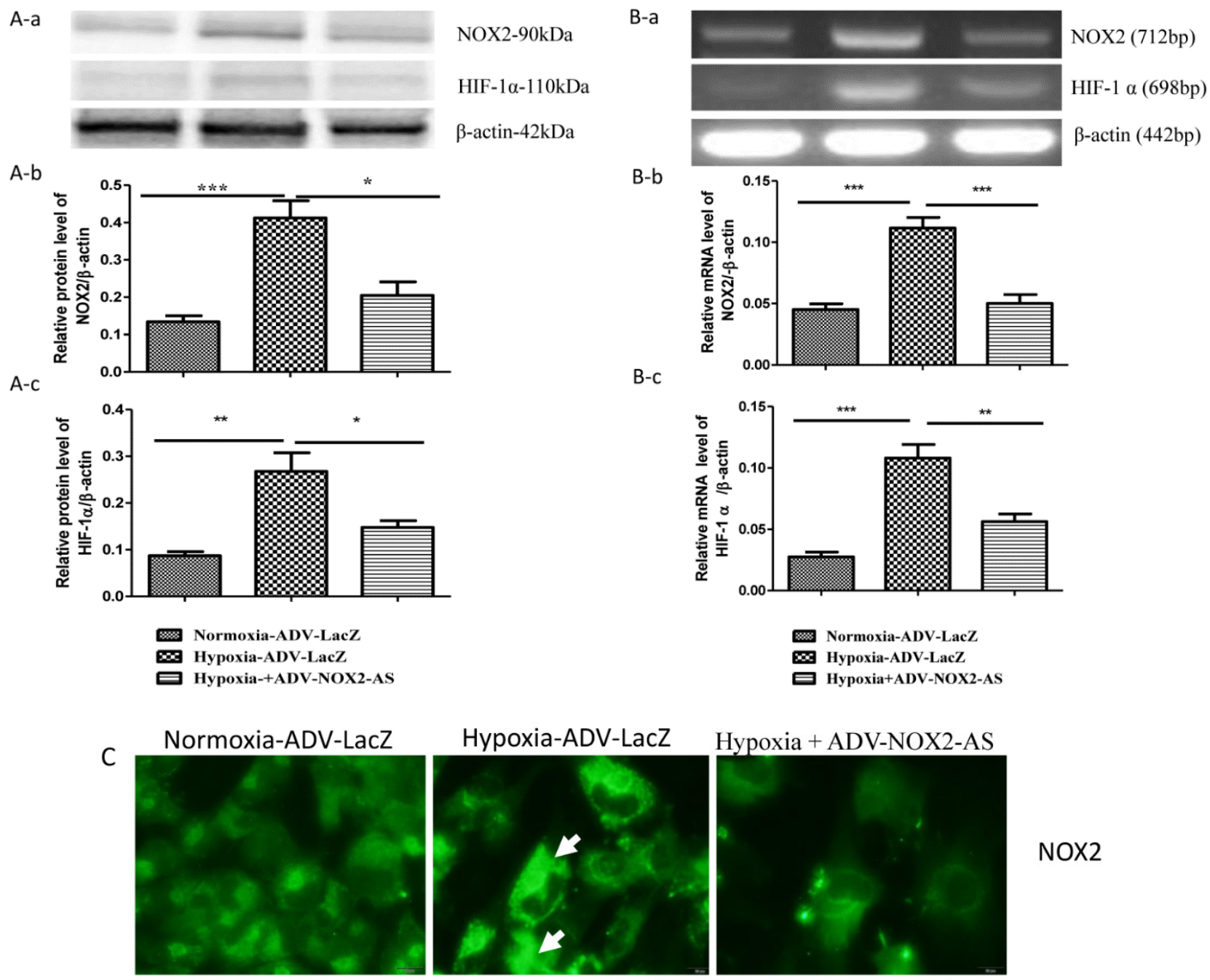

NOX2
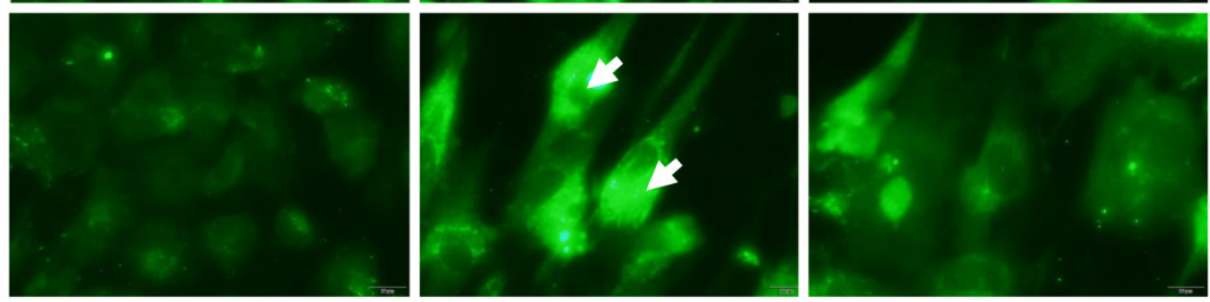

HIF-1 $\alpha$

Fig.2 Expression levels of NOX2 and HIF-1 a protein and mRNA. A-a, Representatives of western blot bands. A-b, Quantification of NOX2 protein expression. A-c, Quantification of HIF-1 a protein expression. B-a, Representatives of RT-PCR bands. B-b, Quantification of NOX2 mRNA expression. B-c, Quantification of HIF-1 a mRNA expression. ${ }^{*} \mathrm{P}<0.05 ;{ }^{*} \mathrm{P}<0.01 ; * * * \mathrm{P}<0.001$. The results were performed in four independent experiments. C, In situ NOX2 and HIF-1 a protein expression. Arrows show positive stain in green. Scale bar $=20 \mu \mathrm{m}$, Original magnification: $400 \mathrm{x}$.

\section{ADV-NOX2-AS diminished superoxide generation in hypoxia-induced cardiomyocytes}

In the present study, NADPH oxidase activity was measured using lucigenin-enhanced method. The result showed that ADV- NOX2-AS blocked hypoxia-induced superoxide generation in cardiomyocytes (Fig.3A). DHE, by virtue of its ability to freely permeate cell membranes, is used extensively to monitor superoxide production [28-30]. Upon reaction with superoxide anions, DHE forms a red fluorescent product (ethidium) which intercalates with DNA [31, 32]. DHE is perhaps the most specific dye for detection of essentially superoxide radicals, but may be affected by cell DNA content [33]. Cell DNA was extracted using genomic DNA isolation kit (Qiagen). The content of DNA was measured with NanoDrop spectrophotometer (Bio-Rad). There was no difference between ADV-LAcZ and ADVNOX2-AS treated cells (data not shown). Interestingly, the ethidium content was increased in hypoxia-ADV-LacZ treated cardiomyocytes compared with the control cells treated with 
normoxia-ADV-LacZ. While in hypoxia-induced cardiomyocytes transduced with ADV-NOX2 -AS, the ethidium content remained no change (Fig.3B).

\section{ADV-NOX2-AS protected cardiomyocytes from hypoxia-induced apoptosis}

Cells initiate intracellular apoptotic signaling in response to a stress, which may bring about cell suicide. The apoptosis was evaluated by flow cytometry (Annexin V stained) and TUNEL assay. Figure 4 demonstrated that hypoxia increased apoptosis in cardiomyocytes, while NOX2 -AS protected the cells from hypoxia-induced apoptosis.

A

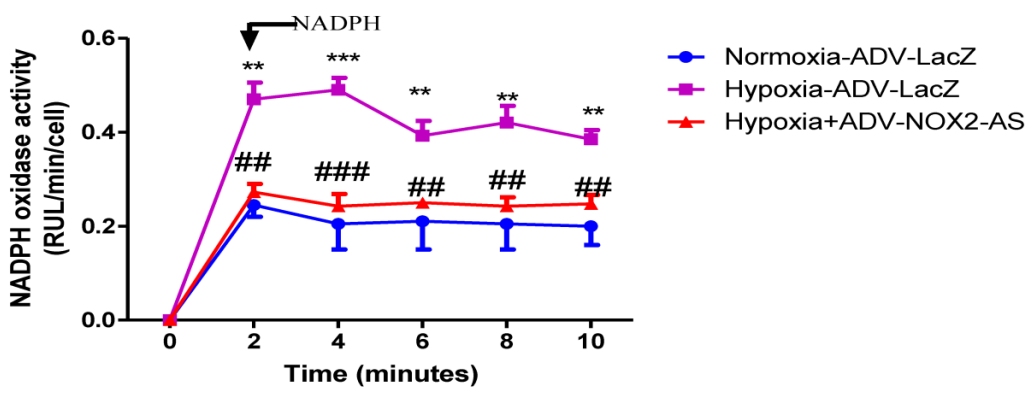

B

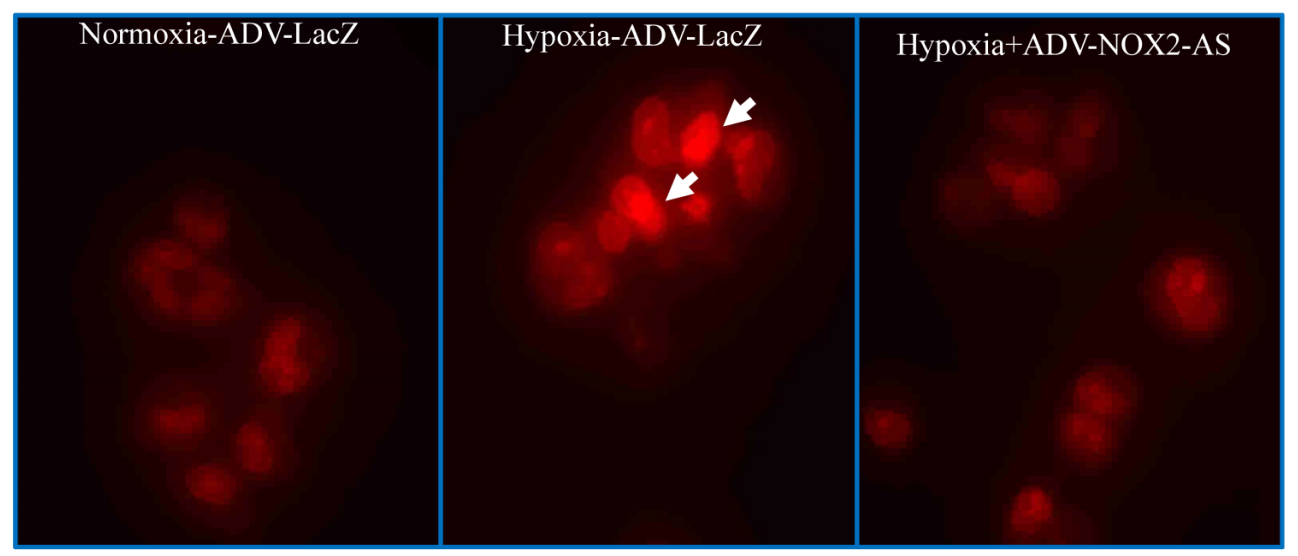

Fig.3 NADPH oxidase activity and in situ superoxide generation (DHE). A, NADPH oxidase activity. B, DHE stain of in situ superoxide generation. Arrows show $\mathrm{DHE}$ stain in red. $* * \mathrm{P}<0.01 ; * * * \mathrm{P}<0.001$. The data show here from four independent experiments.

A

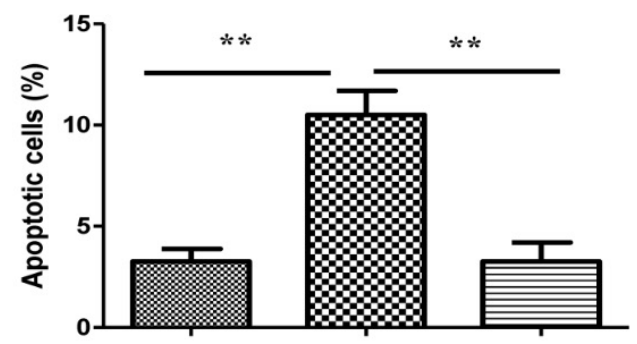

$\approx$ Normoxia-ADV-LacZ

Exo Hypoxia-ADV-LacZ

Eypoxia+ADV-NOX2-AS

B

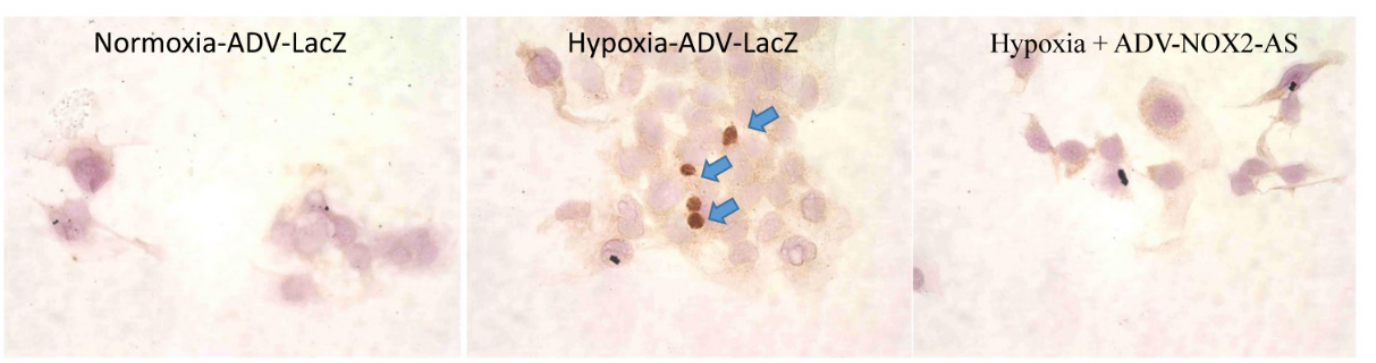

Fig.4. ADV-NOX2-AS attenuated apoptosis in hypoxia-induced cardiomyocytes. A, The percentage of apoptotic cells in Annexin V-based flow cytomertry. B, in situ IHC in TUNEL assay. Positive apoptotic cells (arrows) show in brown. **P<0.01. The data show here from four independent experiments. 


\section{Discussion}

In this study, we clearly demonstrated that adenovirus delivery of rat NOX2 antisense prevented hypoxia-induced increase in NOX2 expression in rat cardiomyocytes. It has been reported that intermittent hypoxia $(\mathrm{IH})$ caused increase in NOX2-derived ROS generation and thus cardiovascular morbidities [34]. In human ischemic heart failure, $\operatorname{NAD}(\mathrm{P}) \mathrm{H}$ oxidase-linked ROS activity was elevated [35], indicating that ROS plays an important role in ischemic myocardium infarction. In this study, we mimicked heart ischemia using Cobalt Chloride hexahydrate in order to induce hypoxia in rat cardiomyocytes. Again, superoxide, a major source of NOX-derived ROS, and $\mathrm{NAD}(\mathrm{P}) \mathrm{H}$ activity were in hypoxia rat cardiomyocytes. NOX2 antisense attenuated the increase in superoxide generation and NADPH activity, suggesting that NOX2 is a critical factor involving in ischemic myocardium infarction.

Myocardium infarction also stabilized hypoxia-inducible transcription factor HIF-1a, a major pathway controlling gene expression in response to oxygen levels [36].

In this study, we used ADV-NOX2-AS to silence the NOX2 expression, resulting in a decrease in hypoxia-induced cardiomyocyte apoptosis. We showed that NOX2, an oxidative stress marker, was upregulated in hypoxia cardiomyocytes. Meanwhile, the hypoxia-inducible transcription factor HIF-1a was also upregulated in hypoxia condition. While, ADV-NOX2-AS prevented hypoxia-induced oxidative stress and cardiomyocyte apoptosis, indicating that NOX2 antisense may serve as a powerful approach for the prevention of heart ischemia (hypoxia) related oxidative stress and apoptosis.

Adenovirus (ADV) is a family of DNA viruses that can infect both dividing and non-dividing cells. ADV vector is a powerful tool for in vitro study of gene therapy. The cells infected with recombinant adenovirus can express the therapeutic gene but, because essential genes for viral replication are deleted, the vector cannot replicate [37]. However, these vectors can infect cells in vivo to express high levels of the exogenous gene. Unfortunately, this expression only lasts for a short time (5-10 days post-infection) [37]. The adeno-associated virus (AAV) is also a suitable vector for long term in vivo study [38]. We will use AAV vector for the following in vivo study.

In summary, ADV-NOX2-AS successfully inhibited hypoxia-induced oxidative stress and apoptosis in cardiomyocyte in vitro. This finding indicates that NOX2 may be a targeting candidate for the therapies in heart ischemia diseases.

\section{Perspectives}

The prevalence of cardiovascular diseases has increased worldwide. This study yields 2 significant findings in the prevention of hypoxia related heart ischemia. First, hypoxia induces the generation of oxidative stress and cardiomyocyte apoptosis. Second, inhibition of NOX2 expression attenuates oxidative stress and cardiomyocyte apoptosis in hypoxia-induced cardiomyocytes. These findings suggest that NOX2 may play a critical role in heart ischemia and that inhibition of NOX2 may be a potential therapeutic strategy for heart ischemic diseases.

\section{Abbreviations}

AAV: adeno-associated virus; ADV: adenovirus; AS: antisense; CM: complete medium; DHE: dihydroethidium; HIF-1a: hypoxia-inducible factor-1 alpha; NADPH: nicotinamide adenine dinucleotide 3-phosphate; PS: phosphatidylserine; TdT: terminal deoxynucleotidyl transferase; TUNEL: TdT-mediated dUTP nick end labeling.

\section{Acknowledgment}

This study was supported by the National Natural Science Foundation of China (81500181).

\section{Competing Interests}

The authors have declared that no competing interest exists.

\section{References}

1. Rakoczy PE. Antisense DNA technology. Methods in molecular medicine. 2001; 47: 89-104.

2. Wagner RW. Gene inhibition using antisense oligodeoxynucleotides. Nature. 1994; 372: 333-5.

3. Sumimoto H, Miyano K, Takeya R. Molecular composition and regulation of the Nox family NAD(P)H oxidases. Biochemical and biophysical research communications. 2005; 338: 677-86.

4. Serrano F, Kolluri NS, Wientjes FB, Card JP, Klann E. NADPH oxidase immunoreactivity in the mouse brain. Brain research. 2003; 988: 193-8.

5. Javeshghani D, Magder SA, Barreiro E, Quinn MT, Hussain SN. Molecular characterization of a superoxide-generating $\mathrm{NAD}(\mathrm{P}) \mathrm{H}$ oxidase in the ventilatory muscles. American journal of respiratory and critical care medicine. 2002; 165: 412-8.

6. Reinehr R, Becker S, Eberle A, Grether-Beck S, Haussinger D. Involvement of NADPH oxidase isoforms and Src family kinases in CD95-dependent hepatocyte apoptosis. The Journal of biological chemistry. 2005; 280: 27179-94.

7. Gorlach A, Brandes RP, Nguyen K, Amidi M, Dehghani F, Busse R. A gp91phox containing NADPH oxidase selectively expressed in endothelial cells is a major source of oxygen radical generation in the arterial wall. Circulation research. 2000; 87: 26-32.

8. Jones SA, O'Donnell VB, Wood JD, Broughton JP, Hughes EJ, Jones OT. Expression of phagocyte NADPH oxidase components in human endothelial cells. The American journal of physiology. 1996; 271: H1626-34.

9. Li JM, Shah AM. Intracellular localization and preassembly of the NADPH oxidase complex in cultured endothelial cells. The Journal of biological chemistry. 2002; 277: 19952-60.

10. Piccoli C, Ria R, Scrima R, Cela O, D'Aprile A, Boffoli D, et al. Characterization of mitochondrial and extra-mitochondrial oxygen consuming reactions in human hematopoietic stem cells. Novel evidence of the occurrence of NAD $(\mathrm{P}) \mathrm{H}$ oxidase activity. The Journal of biological chemistry. 2005; 280 : 26467-76.

11. Heymes C, Bendall JK, Ratajczak P, Cave AC, Samuel JL, Hasenfuss G, et al. Increased myocardial NADPH oxidase activity in human heart failure. Journal of the American College of Cardiology. 2003; 41: 2164-71. 
12. Krijnen PA, Meischl C, Hack CE, Meijer CJ, Visser CA, Roos D, et al. Increased Nox2 expression in human cardiomyocytes after acute myocardial infarction. Journal of clinical pathology. 2003; 56: 194-9.

13. Thannickal VJ, Fanburg BL. Reactive oxygen species in cell signaling. American journal of physiology Lung cellular and molecular physiology. 2000; 279: L1005-28.

14. Gorlach A, Dimova EY, Petry A, Martinez-Ruiz A, Hernansanz-Agustin P, Rolo AP, et al. Reactive oxygen species, nutrition, hypoxia and diseases: Problems solved? Redox biology. 2015; 6: 372-85.

15. Davies KJ. Oxidative stress: the paradox of aerobic life. Biochemical Society symposium. 1995; 61: 1-31.

16. Ide $\mathrm{T}$, Tsutsui $\mathrm{H}$, Kinugawa $\mathrm{S}$, Utsumi $\mathrm{H}$, Kang $\mathrm{D}$, Hattori $\mathrm{N}$, et al. Mitochondrial electron transport complex I is a potential source of oxygen free radicals in the failing myocardium. Circulation research. 1999; 85: 357-63.

17. Guzy RD, Hoyos B, Robin E, Chen H, Liu L, Mansfield KD, et al. Mitochondrial complex III is required for hypoxia-induced ROS production and cellular oxygen sensing. Cell metabolism. 2005; 1: 401-8.

18. Lee SH, Wolf PL, Escudero R, Deutsch R, Jamieson SW, Thistlethwaite PA. Early expression of angiogenesis factors in acute myocardial ischemia and infarction. The New England journal of medicine. 2000; 342: 626-33.

19. O'Donnell BV, Tew DG, Jones OT, England PJ. Studies on the inhibitory mechanism of iodonium compounds with special reference to neutrophil NADPH oxidase. The Biochemical journal. 1993; 290 (Pt 1): 41-9.

20. Simons JM, Hart BA, Ip Vai Ching TR, Van Dijk H, Labadie RP. Metabolic activation of natural phenols into selective oxidative burst agonists by activated human neutrophils. Free radical biology \& medicine. 1990; 8: 251-8.

21. Diatchuk V, Lotan O, Koshkin V, Wikstroem P, Pick E. Inhibition of NADPH oxidase activation by 4-(2-aminoethyl)-benzenesulfonyl fluoride and related compounds. The Journal of biological chemistry. 1997; 272: 13292-301.

22. Kojima S, Nomura T, Icho T, Kajiwara Y, Kitabatake K, Kubota K. Inhibitory effect of neopterin on NADPH-dependent superoxide-generating oxidase of rat peritoneal macrophages. FEBS letters. 1993; 329: 125-8.

23. Meischl C, Krijnen PA, Sipkens JA, Cillessen SA, Munoz IG, Okroj M, et al. Ischemia induces nuclear NOX2 expression in cardiomyocytes and subsequently activates apoptosis. Apoptosis: an international journal on programmed cell death. 2006; 11: 913-21.

24. Gottlieb RA, Burleson KO, Kloner RA, Babior BM, Engler RL. Reperfusion injury induces apoptosis in rabbit cardiomyocytes. The Journal of clinical investigation. 1994; 94: 1621-8.

25. Wu D, Yotnda P. Induction and testing of hypoxia in cell culture. Journal of visualized experiments: JoVE. 2011.

26. Piret JP, Mottet D, Raes M, Michiels C. $\mathrm{CoCl} 2$, a chemical inducer of hypoxia-inducible factor- 1 , and hypoxia reduce apoptotic cell death in hepatoma cell line HepG2. Annals of the New York Academy of Sciences. 2002; 973: 443-7.

27. Dinnen RD, Mao Y, Fine RL. The use of fluorescent probes in the study of reactive oxygen species in pancreatic cancer cells. Methods in molecular biology. 2013; 980: 321-9.

28. Bindokas VP, Jordan J, Lee CC, Miller RJ. Superoxide production in rat hippocampal neurons: selective imaging with hydroethidine. The Journal of neuroscience: the official journal of the Society for Neuroscience. 1996; 16: 1324-36.

29. Li N, Ragheb K, Lawler G, Sturgis J, Rajwa B, Melendez JA, et al. Mitochondrial complex I inhibitor rotenone induces apoptosis through enhancing mitochondrial reactive oxygen species production. The Journal of biological chemistry. 2003; 278: 8516-25.

30. Rivera A, Maxwell SA. The p53-induced gene-6 (proline oxidase) mediates apoptosis through a calcineurin-dependent pathway. The Journal of biological chemistry. 2005; 280: 29346-54.

31. Rothe $G$, Valet $G$. Flow cytometric analysis of respiratory burst activity in phagocytes with hydroethidine and $2^{\prime}, 7^{\prime}$-dichlorofluorescin. Journal of leukocyte biology. 1990; 47: 440-8.

32. Carter WO, Narayanan PK, Robinson JP. Intracellular hydrogen peroxide and superoxide anion detection in endothelial cells. Journal of leukocyte biology. 1994; 55: 253-8.

33. Robinson KM, Janes MS, Pehar M, Monette JS, Ross MF, Hagen TM, et al. Selective fluorescent imaging of superoxide in vivo using ethidium-based probes. Proceedings of the National Academy of Sciences of the United States of America. 2006; 103: 15038-43.

34. Yuan G, Khan SA, Luo W, Nanduri J, Semenza GL, Prabhakar NR. Hypoxia-inducible factor 1 mediates increased expression of NADPH oxidase-2 in response to intermittent hypoxia. Journal of cellular physiology. 2011; 226: 2925-33.

35. Maack C, Kartes T, Kilter H, Schafers HJ, Nickenig G, Bohm M, et al. Oxygen free radical release in human failing myocardium is associated with increased activity of rac1-GTPase and represents a target for statin treatment. Circulation. 2003; 108: 1567-74.

36. Wang GL, Jiang BH, Rue EA, Semenza GL. Hypoxia-inducible factor 1 is a basic-helix-loop-helix-PAS heterodimer regulated by cellular O2 tension. Proceedings of the National Academy of Sciences of the United States of America. 1995; 92: 5510-4.

37. Verma IM, Somia N. Gene therapy -- promises, problems and prospects. Nature. 1997; 389: 239-42

38. Shyam D, Berns KI. Gene therapy using adeno-associated virus vectors. Clinical Microbiology Reviews. 2008; 21: 583-93. 